Journal for

ImmunoTherapy of Cancer

\title{
For whom the T cells troll? Bispecific T- cell engagers in glioblastoma
}

\author{
Kirit Singh, ${ }^{1,2,3}$ Kelly M Hotchkiss, ${ }^{1,3}$ Aditya A Mohan, ${ }^{1}$ Jessica L Reedy, ${ }^{1,3}$ \\ John H Sampson, ${ }^{1,2,3}$ Mustafa Khasraw (1) 1,3,4
}

To cite: Singh K, Hotchkiss KM, Mohan AA, et al. For whom the T cells troll? Bispecific Tcell engagers in glioblastoma. Journal for ImmunoTherapy of Cancer 2021;9:e003679. doi:10.1136/jitc-2021-003679

Accepted 25 0ctober 2021

\section{Check for updates}

(c) Author(s) (or their employer(s)) 2021. Re-use permitted under CC BY-NC. No commercial re-use. See rights and permissions. Published by BMJ.

${ }^{1}$ Department of Neurosurgery, Duke University, Durham, North Carolina, USA

${ }^{2}$ Biomedical Engineering, Duke Universtiy, Durham, NC, USA

${ }^{3}$ Brain Tumor Immunotherapy

Program, Duke University,

Durham, NC, 27703

${ }^{4}$ Duke Cancer Institute, Durham, North Carolina, USA

Correspondence to

Dr Mustafa Khasraw; mustafa.khasraw@duke.edu

\section{ABSTRACT}

Glioblastoma is the the most common primary brain tumor in adults. Onset of disease is followed by a uniformly lethal prognosis and dismal overall survival. While immunotherapies have revolutionized treatment in other difficult-to-treat cancers, these have failed to demonstrate significant clinical benefit in patients with glioblastoma. Obstacles to success include the heterogeneous tumor microenvironment (TME), the immune-privileged intracranial space, the blood-brain barrier (BBB) and local and systemic immunosuppressions. Monoclonal antibodybased therapies have failed at least in part due to their inability to access the intracranial compartment. Bispecific T-cell engagers are promising antibody fragment-based therapies which can bring $T$ cells close to their target and capture them with a high binding affinity. They can redirect the entire repertoire of $T$ cells against tumor, independent of T-cell receptor specificity. However, the multiple challenges posed by the TME, immune privilege and the BBB suggest that a single agent approach may be insufficient to yield durable, long-lasting antitumor efficacy. In this review, we discuss the mechanism of action of Tcell engagers, their preclinical and clinical developments to date. We also draw comparisons with other classes of multispecific antibodies and potential combinations using these antibody fragment therapies.

\section{INTRODUCTION}

Patients with glioblastoma have a poor prognosis with a median survival of approximately 16 months. $^{1-3}$ Advances in survival have been minimal since the mid-2000s, despite improvements in surgical techniques, radiation therapy and the advent of therapies such as tumor-treating fields. ${ }^{2}$ Immunotherapy has been evaluated as one potential solution. Immune checkpoint inhibition (ICI) therapies targeting programmed death-1 (PD-1) and its ligand, programmed death ligand-1 (PD-L1), have improved outcomes in malignancies such as melanoma even when it has metastasized to the brain. ${ }^{4}$ However, similar outcomes have been elusive in glioblastoma, reflecting the complex mechanisms of immune suppression and evasion that it possesses. ${ }^{56}$

Currently, systemically delivered antibodybased immunotherapies approved for patients with cancer falls broadly into two categories. ICIs are monoclonal antibodies (mAbs) which inhibit immune checkpoint signaling. Bispecific antibodies tether tumor cells to T lymphocytes (cytotoxic T lymphocytes (CTLs)) to induce cytolysis, as well as activate innate immune pathways via nonspecific binding to the tail region of the antibody (fragment crystallizable region, Fc). ${ }^{78}$ To exert their therapeutic effect in glioblastoma, these therapies must transit the bloodbrain barrier (BBB) before reinvigorating immune cells that may have been rendered inert by the tumor microenvironment (TME). While some systemically administered antibodies may be able to penetrate the $\mathrm{BBB}$, the concentrations necessary to produce effects in the brain TME are unknown. ${ }^{9}$ This intracranial bioavailability may therefore only reflect a small fraction of the total administered dose.

One approach to bypass the BBB involves the direct administration of immunotoxins via convection-enhanced delivery (CED). ${ }^{10-12}$ These are fusion proteins which consist of an antibody fragment that binds the target cell and a protein toxin fragment which induces cytolysis. ${ }^{13}{ }^{14}$ However, this approach is invasive and can be hampered by unequal drug distribution. ${ }^{1516}$ A newer approach involves the use of a fusion protein that can be delivered systemically-bispecific T-cell engagers. These consist of two antigen-binding variable fragments that tether the tumor cells to CTLs but differ from their antibody parents in that they do not possess the constant (Fc). As they are smaller in size than traditional mAbs, they may more easily penetrate the BBB. ${ }^{17} 18$ This small size also allows $\mathrm{T}$ cells to closely bind their target, resulting in a high-affinity immune synapse. ${ }^{19}$ Bispecific T-cell engagers also are highly potent, exerting a therapeutic effect at nanomolar concentrations. ${ }^{20}$ Bispecific T-cell engagers can therefore potentially access this immune privileged compartment more readily while also exerting a highly 
potent effect even at low concentrations. This combination makes it an ideal candidate for an immunotherapybased approach in glioblastoma. However, glioblastoma is uniquely shielded from the immune system due to its location within the central nervous system (CNS). While this privilege is not absolute, a significant proportion of tumors have been noted to be devoid of any tumorinfiltrating lymphocytes (TILs) that can be redirected by bispecific T-cell engagers. ${ }^{21} 22$ In those tumors that do demonstrate invasion by TILs, they are often induced to be dysfunctional and anergic by the suppressive TME. ${ }^{23}$ Isocitrate dehydrogenase (IDH) wild-type gliomas also lack a universally expressed tumor-specific antigen which may result in antigen escape and tumor regrowth, making targeting of precisely engineered therapies difficult. ${ }^{24-26}$

Heterogeneity and local immune suppression have also frustrated the use of bispecific T-cell engagers in other solid malignancies, and to date, these agents have only been approved by the US Food and Drug Administration (FDA) for the treatment of acute lymphocytic leukemia (blinatumomab, Amgen). ${ }^{2728}$ In this review, we will discuss the current landscape for bispecific T-cell engagers in glioblastoma, as well as the challenges they face, and describe potential approaches to overcome these.

\section{DESIGN AND MECHANISM OF ACTION}

Bispecific T-cell engagers consist of two linked antigenbinding variable fragments devoid of the constant domain of their parent antibody. These fragments are linked by short flexible linker regions ${ }^{29}$ resulting in a small construct (approximately $55 \mathrm{kDa}$ ), which can bring CTLs into close proximity to the target cell, resulting in a high binding affinity. ${ }^{18}{ }^{30} \mathrm{CD} 8^{+}$CTLs, like all $\mathrm{T}$ cells, express variable T-cell receptors (TCRs) associated with invariable CD3 subunits. Bispecific T-cell engagers typically link tumor-associated antigens (TAAs) with the CD3€ unit of the TCR complex, thereby engaging $\mathrm{T}$ cells to form a synapse on the surface of the tumor cell. The T cell is activated, triggering cell death signaling pathways with the subsequent release of granzymes and perforins. ${ }^{31}$ Given that bispecific T-cell engagers engage the $\mathrm{CD} 3 €$ unit, this means that they are not limited by TCR specificity and can potentially redirect the entire repertoire of $\mathrm{T}$ cells. This may also involve $\mathrm{T}$ cells that have reactivity against other tumor antigens, leading to epitope spreading. T-cell activation also results in the expansion of the $\mathrm{CD}^{+} \mathrm{T}$-cell compartment, driven in the context of T-cell engagers by an increase in cytotoxic $\mathrm{CD}^{+} \mathrm{T}$ effector memory cells. ${ }^{32}$ Importantly, this occurs in a TCR-peptide-major histocompatibility complex (MHC) independent manner, which avoids the potential for immunotherapy driven downregulation of MHC-I and immune escape ${ }^{20}$ Furthermore, brain bispecific T-cell engager (BRiTE) has been shown to redirect local regulatory $\mathrm{T}$ cell $\left(\mathrm{T}_{\text {reg }}\right)$ to kill glioblastoma tumor in vitro via the granzyme-perforin pathway, potentially overcoming a key element of the immunosuppressive microenvironment. ${ }^{33} 34$
Bispecific T-cell engagers offer immunotherapy in a manufacturing format which is both scalable and standardizable. In contrast to chimeric antigen receptor (CAR) $\mathrm{T}$ cells, T-cell engagers do not require initial lymphodepletion and ex vivo expansion of autologous cells which require transduction (that may potentially lead to variable yields). ${ }^{35}$ Owing to their relatively simple structure of a single-chain polypeptide, bispecific T-cell engagers can be batch manufactured in large quantities using well-established commercial processes such as expression via Chinese hamster ovary cells (eg, as used for single-chain bispecific agents targeting CD19). ${ }^{37} 38$ While this requires generating a construct that can be readily expressed, these T-cell engagers can be processed into a format without dosing variability, offering an 'offthe-shelf' form of immunotherapy.

Further, bispecific T-cell engagers have been shown to drive $\mathrm{T}$ cell-mediated cell kill both in vivo and in vitro at very low concentrations $(10-100 \mathrm{pg} / \mathrm{mL})$ and at low effector to target cell ratios (E:Ts) in hematological malignancies $(<1: 90) .{ }^{39} 40$ Single-chain bispecific antibody fragments have also been demonstrated in vitro to exhibit 100 000-fold superior antitumor cytotoxicity compared with conventional mAbs. ${ }^{19}{ }^{41}$ However, it is important to note that in vitro data may not accurately reflect the characteristics of a therapeutic in vivo as retrospective work comparing potency between the two settings for antibodies have reported large discrepancies in binding behavior. ${ }^{42}$ Many in vitro potency assays are unable to fully account for interactions with the target in the steady state and therefore fully evaluate ligand-target kinetics. ${ }^{43}$ Nevertheless, the potential for a highly potent immunotherapy that can redirect the entire host repertoire of $\mathrm{T}$ cells and be manufactured in a consistent and scalable fashion is a highly attractive prospect. However, significant challenges remain which we will discuss in the following section.

\section{DEVELOPMENT AND CHALLENGES FACING T-CELL ENGAGERS IN INTRACRANIAL MALIGNANCY Choosing the right target: is one enough?}

Developing a potent and effective T-cell engager therapy for intracranial malignancy faces many challenges (summarized in figure 1). The ideal CTL-based approach requires the identification of a universally expressed and specific tumor antigen, but this is an unrealistic expectation for glioblastoma. While some subsets of glioma share clonal neoepitopes (IDH1-R132H) and have been targeted by vaccination in humans, this is presented in an MHC class II-restricted manner and does not elicit a CD8 ${ }^{+}$ CTL response. ${ }^{44}$

One attractive target is epidermal growth factor receptor variant III (EGFRvIII), which is specific to glioblastoma and is not expressed in non-tumor tissue. Epidermal growth factor receptors (EGFRs) are involved in deregulated cancer signaling pathways, leading to atypical proliferation and growth of tumor cells. ${ }^{45}$ EGFRvIII is the 


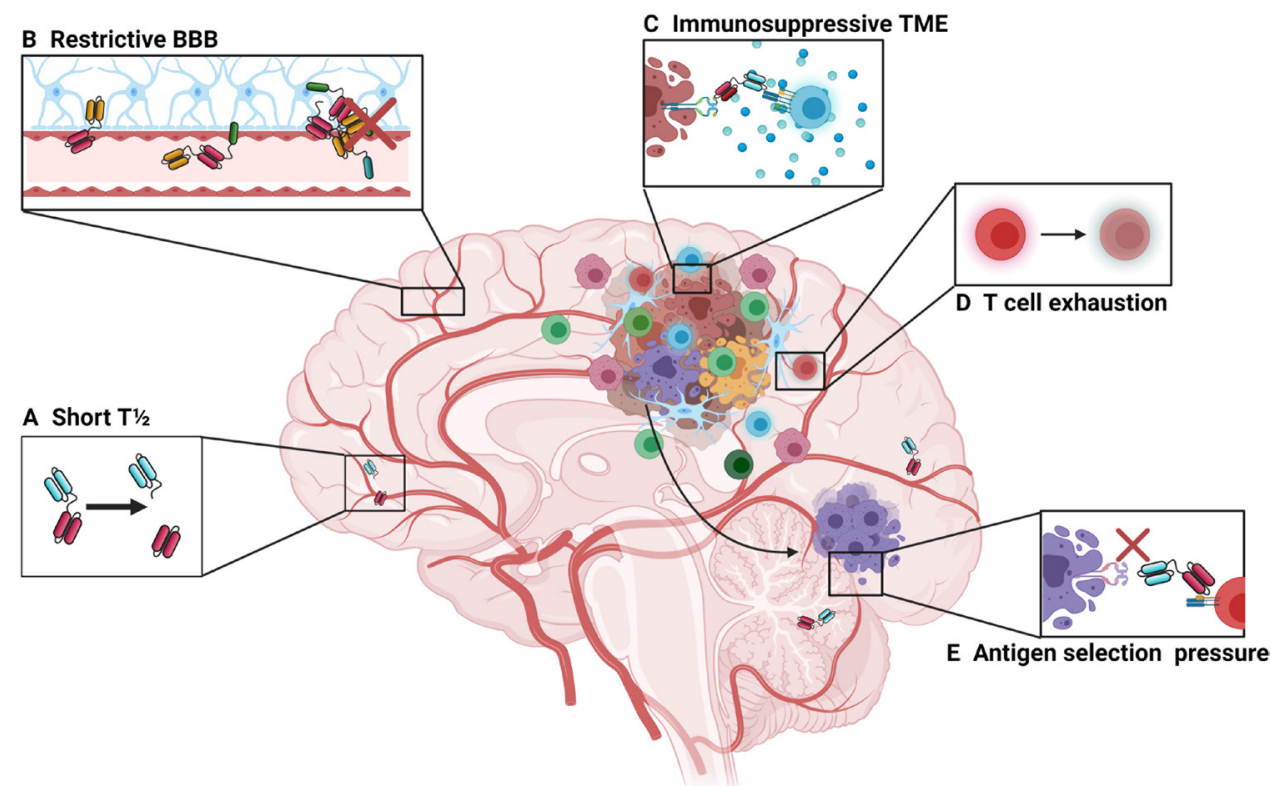

Figure 1 Barriers to bispecific T-cell engager therapies in the intracranial environment. (A) First-generation bispecific T-cell engagers are small in size (approximately $55 \mathrm{kDa}$ ), which makes them prone to rapid clearance, giving them a short plasma half-life of approximately 2.5 hours. ${ }^{63}$ This limits their time to exert their therapeutic effect and can pose a challenge for clinical administration, necessitating continuous infusion strategies. Newer designs involve the use of additional Fc regions, full size antibody constructs or the addition of albumin-binding domains. However, these also increase the size of the construct and may affect trafficking dynamics at the BBB. (B) The BBB prevents the passive movement of cells and molecules that could potentially damage the central nervous system. While the small size of bispecific T-cell engagers makes them theoretically more able to cross the BBB compared with larger, full-sized monoclonal antibodies, the trafficking of effector $T$ cells may be restricted by the BBB. (C) High levels of immunosuppression surrounding tumor may prevent or limit T-cell activation following T-cell engagement. (D) Tumor-infiltrating lymphocytes may become exhausted and anergic, which is driven in part by tumor cells expressing programmed death ligand-1 along with myeloid-derived suppressor cells. (E) Glioblastoma lacks a uniformly expressed major histocompatibility complex-independent tumor-specific antigen which limits bispecific therapy as there may be selection pressure on those tumor cells expressing the target antigen, leading to outgrowth of antigen-negative cells. BBB, blood-brain barrier; TME, tumor microenvironment.

most common variant which is not presented in an MHCdependent manner, but is present in only $20 \%-30 \%$ of patients and is not expressed in all tumor cells. ${ }^{46}$ Scott $e t$ al demonstrated that systemically delivered radiolabeled antibodies specific to EGFRvIII were taken up in high levels by tumors in patients with glioblastomas, indicating their ability to accumulate intracranially. ${ }^{47}$ However, it is notable that this effect was only seen in one of eight patients studied. This may reflect penetration of a radiolabeled antibody through the diseased BBB. However, disruption of the $\mathrm{BBB}$ is not uniform in glioblastoma, and there may be regions of immune privileged tumor shielded by intact portions of barrier. ${ }^{48}$ Further work to determine optimal delivery of systemic bispecific T-cell therapy across intact and disrupted BBB is required.

First in-human trials of EGFRvIII-specific CAR $\mathrm{T}$ cells found that disease regression could be induced in a specific manner, with no off-target effects on wild-type EGFR. ${ }^{49}$ However, O'Rourke et al demonstrated antigen loss and a lack of persistent effector T-cell activity in patients treated with EGFRvIII CAR $\mathrm{T}$ cells. ${ }^{24}$ Brown et al similarly reported achieving efficacy in reducing disease burden when targeting the IL13R $\alpha 2$ cell surface receptor but described antigen loss in post-treatment tumor samples taken from patients who had experienced recurrence. ${ }^{26} 50$ While the experience of using bispecific T-cell engagers in clinical glioblastoma is limited, this effect has also been observed with hematological therapies where CD19-negative clones have developed following treatment with blinatumomab or anti-CD19 CAR T cells. ${ }^{51-53}$ Tandem approaches targeting multiple TAAs are one potential strategy to overcome this obstacle. A tandem CAR targeting HER2 and IL13R $\alpha 2$ has been shown to enhance survival and mitigate antigen escape in murine models of glioblastoma. ${ }^{54}$ However, targeting two or more TAAs may ultimately fail if even a small part of the tumor does not express this combination, and such an approach may also significantly increase the risk for off-target toxicity.

Another approach to address heterogeneity may be by inducing partial kill of a tumor, thereby driving antigen shedding by dying tumor cells (epitope spreading). 5556 Concurrent local cytokine production/administration has been shown in vitro and in vivo to drive bystander cell killing, even if those cells in the vicinity are antigen negative. ${ }^{5758}$ However, Krenciute et al described antigen escape still occurring in murine models of glioblastoma when IL13R $\alpha 2$ CAR T cells were induced to express costimulatory interleukin (IL) $-15{ }^{59}$ Choi et al reported efficacy in heterogenous murine glioblastoma when using CAR-T 
cells specific for EGFRvIII but which are also designed to express a bispecific T-cell engagers targeting EGFR wild type. This intracranially administered drug could induce local cytotoxicity, with no EGFR bispecific T-cell engagers detected in the periphery. ${ }^{60}$ Further, bispecific T-cell engagement of CD3 to the target antigen results in an immune synapse more akin to the natural TCR-MHC peptide complex, resulting in secretion of cytokines and promoting differentiation of naïve $\mathrm{T}$ cells to lyse tumor cells, thereby driving a more diverse and efficient immune response..$^{20162}$

\section{Potent but brief killer}

Ensuring persistence of bispecific T-cell engagers to drive ongoing killing at the tumor site is another significant challenge. While the small size of bispecific T-cell engagers allows for them to bring CTLs into close proximity with the target cell, they tend to have a short half-life due to rapid renal clearance (approximately 2.5 hours $^{63}$ ). This rapid clearance can limit drug accumulation, particularly in difficult to access compartments such as the brain. A half-life of just 2.5 hours requires dosing regimens that rely on continuous infusion, often requiring patients to have venous access port systems installed which carry their own associated risks. ${ }^{64}$ Furthermore, the small size can lead to drug stability and aggregation issues. ${ }^{65}$

Approaches to extend the half-life of bispecific T-cell engagers involve giving the construct a higher molecular weight, which would extend the elimination half-life and make this therapy deliverable via serial infusions while maintaining serum levels. ${ }^{66}$ These can involve constructions that add a constant domain to the bispecific structure (as per AMG160 targeting PSMA for prostate cancer), or indeed reverting to full size bispecific antibodies such as approaches targeting ENPP3 in renal cell carcinoma (RCC), prostate cancer (via prostate specific membrane antigen (PSMA) ) or a mixed valency $2+1$ format bispecific antibody targeting claudin- 6 in ovarian cancer. ${ }^{67-70}$

Half-life extended bispecific T-cell engagers are under investigation in a first-in-human phase I study involving patients with B-cell malignancies to evaluate safety and preliminary efficacy (NCT03571828). ${ }^{71}$ However, bispecific T-cell engagers may transit the $\mathrm{BBB}$ more readily due to their small size. Half-life extension modules which increase the molecular weight by adding an Fc domain, or indeed full-size antibody constructs may hinder migration across the BBB. ${ }^{65}$ Other approaches use the addition of a variable fragment of a humanized albumin-binding antibody. ${ }^{72}$ Interestingly, the addition of human serum albumin (HSA) may also aid the transiting of small therapeutics across the BBB, and its use in a combination format with bispecific therapies targeting intracranial malignancies may have a dual benefit. ${ }^{73}$

\section{A hostile microenvironment}

Glioblastoma is surrounded by a highly immunosuppressive stroma, in which regulatory $\mathrm{T}$ cells (CD4 +CD25+FOXP3), tumor-associated macrophages
(TAMs) and myeloid derived suppressor cells are present. ${ }^{56}$ This environment can drive T-cell anergy and apoptosis as well as blunting the impact of innate natural killer (NK) cells. Glioblastoma expresses HLA-G, which inhibits activated NK cells and therefore downregulates their response. ${ }^{75}$ IDH mutant gliomas also demonstrate resistance to NK activity by epigenetically silencing activating receptor ligands. ${ }^{76}$ While NK cells can destroy glioma stem cells, phase III studies using NKs or lymphokine-activated killer cells have failed to improve immune response against immunologically 'cold' solid tumors. $^{77} 78$

More recent attention has turned to addressing causes of T-cell failure in the TME. As mentioned previously, regulatory $\mathrm{T}$ cells are adept at inducing secondary T-cell failure via immunosuppressive molecular factors such as PD-L1 and CTLA-4, LAG-3, TIM-3 and others. ${ }^{79} 80$ However, it is notable that ICI as a monotherapy has failed to confer benefit in patients with glioblastoma. ${ }^{81}$ This may reflect multiple overlapping mechanisms of immune suppression that provide redundancy. Regulatory $\mathrm{T}$ cells inhibit the secretion of T-cell cytokines and proliferation by also exerting a downregulatory effect on the production of IL-2 and interferon- $\gamma{ }^{82}$ Overproduction of IDO-1 by glioma not only recruits regulatory $\mathrm{T}$ cells but also has a metabolic impact on T-cell activity by reducing the amount of tryptophan available in the microenvironment. ${ }^{83}$ While there have been several studies evaluating the use of IDO-1 inhibitors in glioblastoma, including combination approaches against PD-1 and IDO-1 (NCT03707457), phase III evaluations of IDO inhibition in other solid malignancies in the CNS (metastatic melanoma) have failed to demonstrate survival benefit. ${ }^{84}$ However, more recent mechanistic studies suggest that this failure may be due to incomplete blockade of protumorigenic metabolic pathways. Enzymes such as IL-4-induced-1 have also been associated with downstream receptors activated by tryptophan catabolites and whose activity is undisturbed by IDO-1 inhibition. ${ }^{85} 86$

Stromal cells in the microenvironment also produce highly immunosuppressive cytokines such as transforming growth factor beta (TGF- $\beta$ ) and IL- $10 .{ }^{87} 88$ Preferential production of lactate by tumors via anaerobic metabolism (known as the Warburg effect) can decrease CTL activity as well as migration potential. ${ }^{89}$ The tumor itself can drive T-cell dysfunction by producing hypoxiainducing factor-1 alpha (HIF-1a) to promote angiogenesis and proliferation. ${ }^{90} 91$ Overexpression of HIF-1a can also reduce the migration of CTLs via downregulation of CD62L, resulting in their failure to migrate to the tumor site. ${ }^{92}$ Taken together, the aforementioned mechanisms contribute to an 'immune desert' landscape, characterized by few, if any, infiltrating lymphocytes which bispecific T-cell engagers can redeploy against tumor cells. ${ }^{93}$

Novel preclinical approaches include combinatorial inhibition of recognized drivers of T-cell exhaustion such as CTLA-4, LAG-3, TIM-3, or IDO with bispecific T-cell engagers, or triggering costimulatory receptors such 
as 4-1BB, OX40, CD40, or CD27. ${ }^{94}$ More controllable constructs have also been demonstrated preclinically, with the use of switch receptor constructs targeting PD-1 expression, whereby adding CD28 domains can transform a negative signal into a stimulatory one ${ }^{95}$ Work is also under way exploring potential combinatorial cytokine modulation approaches, such as those described in 'armored' CAR T cells which are combined with IL-12, IL-15 or IL-18 for enhanced effect. ${ }^{96-98}$ Should such approaches show promise, these could be translated to the T-cell engager format either as part of the construct or as an adjunct delivered via catheter directly to the tumor. Frewert et al described enhanced CTL activity when infusing IL-1 $\beta$ or interferon- $\gamma$ intratumorally, making this a logical combination with bispecific $\mathrm{T}$ cell engagers. ${ }^{99}$ Antibody mediated blockade of lactate transporters may also aid in combating $\mathrm{T}$ cell dysfunction in the TME, as well as the use of constructs targeting fibroblast activation proteins or expressing heparinase to disrupt immunosuppressive stromal elements. 89100101

\section{PRECLINICAL DEVELOPMENT OF T-CELL ENGAGERS FOR GLIOBLASTOMA}

Murine bispecific T-cell engagers targeting EGFRvIII and CD3€ were first described by Choi et al. ${ }^{102}$ When systemically administered, this construct was found to activate $\mathrm{T}$ cells to generate potent antigen-specific lysis of EGFRvIII expression gliomas in vitro $(\mathrm{p}<0.001)$ at very low concentrations $(10 \mathrm{ng} / \mathrm{mL})$ and at low E:Ts $(1: 2.5)$. While this ratio is lower than the previously mentioned $<1: 90$ for CD19 agents, it is notable that bispecific T-cell engagers may benefit from lower E:T ratios in solid tumors due to the process of additive toxicity, as described by Weigelin et al in murine models of melanoma. ${ }^{103}$ Cytolysis of solid tumor cells may be induced by sequential 'sublethal' interactions between CTLs and tumor cells (such as granzyme B-mediated damage to the nuclear envelope and the creation of double-stranded breaks in DNA). ${ }^{103} 104$ Bispecific T-cell engagers may help to promote this effect on solid tumors by acting as a stabilizing contact which can increase these sublethal CTL interactions at the tumor site. ${ }^{35} 103$ Choi et al also reported that bispecific T-cell engager therapy could redirect $\mathrm{T}_{\text {regs }}$ in vitro to express granzymes and perforins, which may serve to induce further tumor cytolysis. ${ }^{34}$ Accordingly, the use of bispecific T-cell engagers in murine models of intracranial glioma has been shown to achieve durable and complete cures in up to $75 \%$ of mice $(\mathrm{p}<0.05) .{ }^{102}$

Following this, a fully human T-cell engager was described by Gedeon et al. ${ }^{105}$ This fully human construct would avoid potential murine antibody-associated complications such as cytokine release syndrome, unpredictable dose-response relationships, and the formation of human anti-mouse antibodies, leading to rapid clearance of the bispecific T-cell engager from the serum. ${ }^{106-109}$ This fully human bispecific T-cell engager again exhibited specific binding, cytokine release, T-cell activation and proliferation, and in vitro and in vivo tumor cell lysis in murine models of orthotopically implanted glioma. ${ }^{63}$ Schaller et al subsequently conducted preclinical studies to determine the minimum anticipated biological effect level and thus to establish a safe dose for first in-human trials (notably 1000-fold lower than prior in vivo dosages). ${ }^{110}$ This study determined that the theoretical human receptor occupancy was $0.17 \%$, far below industry standard levels. ${ }^{11-113}$ An extended singledose toxicity study in vivo using mice demonstrated no evidence of pathological findings related to the bispecific T-cell engager and no neurological toxicity was exhibited. ${ }^{114}$ Detailed pharmacokinetic analysis demonstrated a relatively short half-life in keeping with other T-cell engagers with a half-life of $8 \mathrm{~min}$ and a terminal half-life of $\sim 2.5$ hours. ${ }^{63}$

\section{CLINICAL DEVELOPMENT OF EGFR T-CELL ENGAGERS FOR GLIOBLASTOMA}

Currently, there are two EGFRvIII targeting T-cell engagers entering phase I trials for glioblastoma. AMG596 is a bispecific T-cell engager (trademarked as BiTE) by AMGEN, which conducted a phase I open-label sequential dose-escalation and dose-expansion trial in humans (NCT03296696). The study evaluated safety, tolerability and pharmacokinetics and pharmacodynamics of AMG596 in patients with both newly diagnosed and recurrent EGFRvIII-positive glioblastoma. ${ }^{115}$ Like blinatumomab, AMG596 is administered via a continuous intravenous infusion. This T-cell engager was to be trialed as both a monotherapy and in combination with AMG404, a proprietary $\mathrm{mAb}$ which blocks binding of the immune checkpoint programmed cell death protein-1 (PD-1). ${ }^{116}$ However, while this study began enrollment in April 2018, it is unclear if ongoing development may progress due to portfolio prioritization. ${ }^{117}$ hEGFRvIII-CD3 bi-scFv (BRiTE) is another EGFRvIII bispecific construct which is entering phase I clinical trials (NCT04903795). This consists of anti-human mAb clones 139 (anti-EGFRvIII) and 28F11 (anti-CD3), both of which have been used safely in the clinical environment previously. ${ }^{118-120}$ This will be trialed as both a monotherapy and in combination with peripheral T-cell infusion. As described, latestage tumors frequently evade immune response due to inducing T-cell anergy and apoptosis. Increased numbers of intratumoral CD8 ${ }^{+}$CTLs have also been associated with favorable outcomes in patients with glioblastoma. ${ }^{121-123}$ Concomitant administration of stimulated CTLs may therefore synergistically enhance the efficacy of this treatment. ${ }^{124}$ The migration of T-cell engagers across the BBB may also be facilitated by activated $T$ cells which adhere to the brain microvascular endothelium and subsequently cross by diapedesis. ${ }^{125}$ Concurrent administration of activated $\mathrm{T}$ cells could therefore enhance the trafficking of bispecific T-cell engagers into the intracranial compartment, increasing their density at the tumor site and thus the therapeutic effect. However, this approach requires 
careful monitoring of toxicity, as the release of inflammatory cytokines in the CNS has been associated with immune effector cell-associated neurotoxicity syndromes (ICANS). This condition manifests as a spectrum of symptoms ranging from lethargy and confusion to seizure and coma. ${ }^{126}$ ICANS has been observed as a potential side effect for bispecific T-cell engagers even without a brain-specific target. Blinatumomab (specific for CD19) has been found to systemically activate T cells which then subsequently cross the BBB in a non-specific manner. It is theorized that these $\mathrm{T}$ cells may then encounter sporadic CD19 expressing target cells in the CNS and then release inflammatory cytokines such as IL-6 and IL- $1 \beta$, which can disrupt the BBB further, allowing for greater ingress of proinflammatory cytokines. ${ }^{125}$ Importantly, this toxicity can be abrogated by the administration of agents such as natalizumab, which prevents T-cell migration across the BBB. $^{125}$

EGFR biarmed activated $\mathrm{T}$ cells (EGFR BATs) is a separate CD3 bispecific approach under investigation targeting EGFRwt. EGFR BATs are T cells that have been coated with cetuximab (a bispecific antibody targeting EGFRwt) and treated with OKT3 to stimulate them. ${ }^{127}$ This approach is currently undergoing phase I clinical trials for safety and toxicity in patients with newly diagnosed glioblastoma alongside standard of care treatment (NCT03344250). Despite targeting EGFRwt, which is expressed at several sites around the body, preliminary data report no dose-limiting toxicity of the four patients treated in the first-dose tier. ${ }^{128} \mathrm{~A}$ summary of these approaches is shown in table 1.

\section{FUTURE APPROACHES}

Given the plethora of targets, agents and obstacles for bispecific T-cell engagers in glioblastoma, it is understandable that new approaches are already under preclinical development (overview shown in figure 2). These consist of both an expansion of the bispecific T-cell engager construct, with more potential antigen targets incorporated, or by combining bispecific T-cell engager therapy with checkpoint inhibitors simultaneously. Given the early stage of preclinical development for many of these approaches, we will discuss the initial findings from multiple malignancies, which may offer insights for future directions in glioblastoma.

\section{Checkpoint inhibitory T-cell engagers (CiTEs) and simultaneous multiple interaction T-cell engagers (SMiTEs)}

CiTEs offer immune checkpoint blockade in the area of interest only by tethering immune checkpoint domains to classical bispecific T-cell engager construct, reducing the chance for on-target, off-tumor effects. ${ }^{129}$ SMiTEs consist of two separate bispecific T-cell engagers targeting separate antigens. These have been used to target both CD3, to induce the lytic synapse as described previously, and CD28, to induce a costimulatory signal for engaged $\mathrm{T}$ cells. Such constructs have been designed using a CD3-TAAxanti-PD-L1-CD28 format to further enhance their activation and overcome potential anergy in a local fashion. ${ }^{130}$ Although CD28 stimulation can have deleterious off-target effects, its combination with a bispecific T-cell engager specific to the tumor site may help to ensure specificity and prevent systemic toxicity. ${ }^{131}$

\section{Trispecific T-cell engagers (TRiTEs)}

Other similar approaches involving CD28 include TRiTEs, which have been found to suppress myeloma growth in a humanized mouse model while also stimulating memory/ effector T-cell proliferation and reducing $\mathrm{T}_{\text {reg }}$ cell numbers in primates. ${ }^{132}$ Bispecific T-cell engagers have also been engineered to include cytokines such as IL-12 to enhance their activity. Do et al described a nanoparticle-based assembly and screening approach before using a modular platform to incorporate the cytokine of interest. ${ }^{133}$ They reported that the optimally lytic architectures favor high $\alpha \mathrm{CD} 3$ to $\alpha \mathrm{TAA}$ ratios, and these are improved linearly by increasing IL-12. Given that many current structures offer a 1:1 binding ratio of CD3 to TAA, it may be that combinatorial structures can increase the binding avidity and enhance effect. The wide variety of potential targets, both in terms of ICI and selecting for other TAAs or cytokine inclusion, may also make simultaneous engagement an attractive proposition for addressing glioblastoma heterogeneity and overcoming immune escape. Another TRiTElike approach is the trispecific T-cell activating construct

Table 1 EGFR targeting T cell engagers for glioblastoma in clinical trials

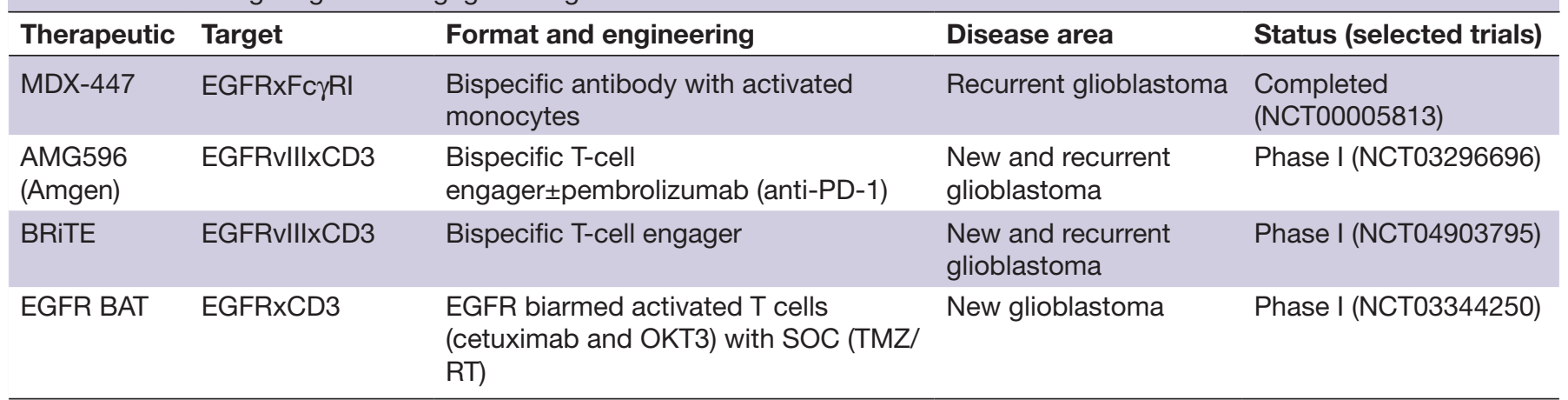

BRiTE, brain bispecific T-cell engager; EGFR, epidermal growth factor receptor; EGFRvIII, epidermal growth factor receptor variant III. 
A

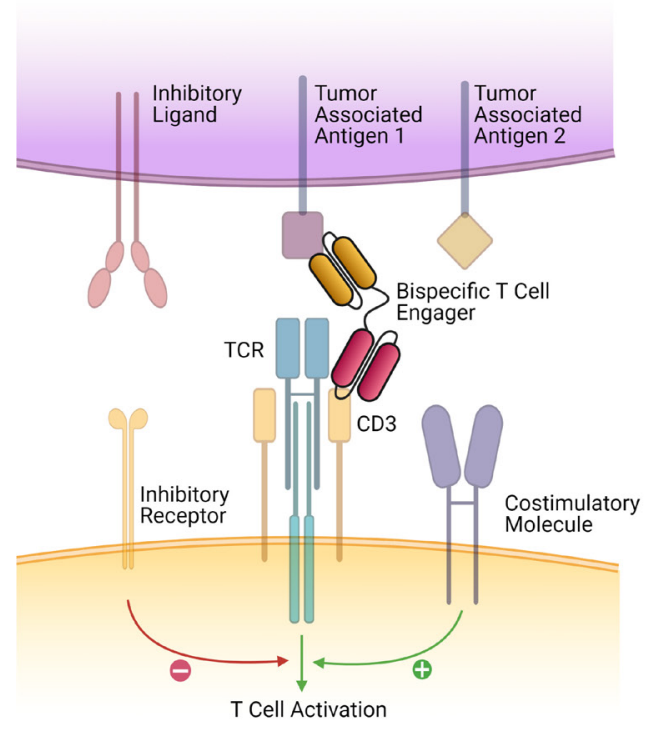

B

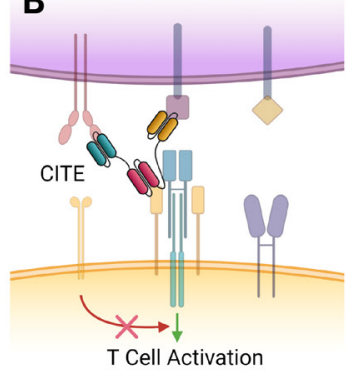

C

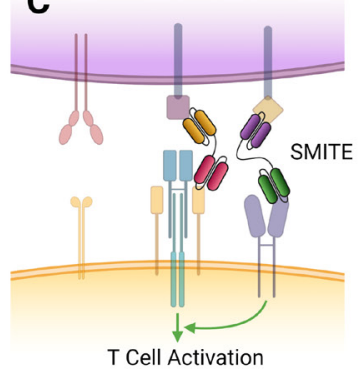

D

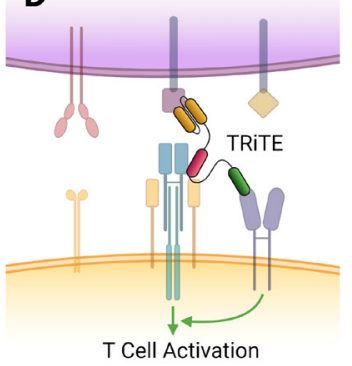

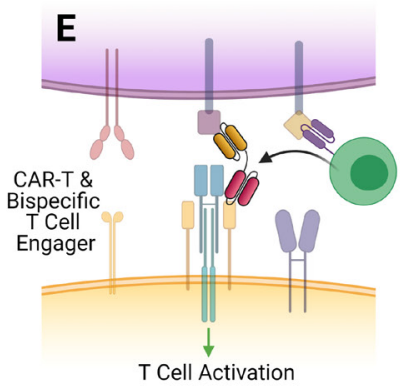

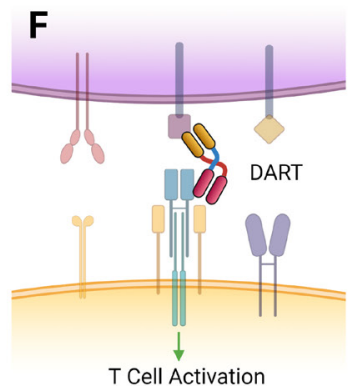

Figure 2 Bispecific T-cell engager constructs and future directions. The 'classical' T-cell engager structure, consisting of two antigen-binding variable fragments, devoid of the Fc domain of their parent antibody, linked by a short flexible linker region. It tethers the epsilon subunit of the T cell to EGFRvill expressing tumor cells, activating the T cell, which then releases granzymes and perforins, resulting in tumor cell death. This approach is currently being evaluated in phase I clinical trials (NCT04903795 and NCT03296696) (B) CiTEs include the extracellular domain of a checkpoint inhibitor (such as PD-1) fused to a traditional T-cell engager scaffold. This allows for synergistic checkpoint blockade alongside T-cell tethering and activation and has demonstrated enhanced efficacy in vitro and in vivo in acute myeloid leukemia (AML). ${ }^{129}$ (C) SMiTEs are constructed from two separate classical T-cell engagers which target separate antigens. These can offer costimulation of tethered T cells and provide regional checkpoint blockade while also offering the traditional lytic effects formed by the tumor-T cell synapse. (D) TRiTEs can tether T cells to the tumor while also delivering costimulatory signals (eg, via interaction with CD28). (E) CAR T cells which can be engineered to secrete T-cell engagers have been described by Choi et al, who developed a bicistronic construct that resulted in expression of a CAR specific for EGFRvIll, which could also secrete T-cell engagers specific for EGFR wild type, which would only have effect in the local tumor environment. These demonstrated promising efficacy against heterogeneous mouse models of glioblastoma.$^{60}$ (F) DART proteins are a novel take on the bispecific construct, where two variable fragment chains are linked by disulfide bonds and non-covalent forces, which may result in greater stability and enhanced cytotoxicity. ${ }^{142} \mathrm{CAR}$, chimeric antigen receptor; CiTE, checkpoint inhibitory T-cell engager; DART, dual-affinity retargeting; EGFR, epidermal growth factor receptor; SMiTE, simultaneous multiple interaction T-cell engager; TCR, T-cell receptor; TRiTE, trispecific T-cell engager.

(TriTAC) platform, which contains three domains that target a TAA, CD3, and HSA. The authors demonstrated that TriTACs have good solid tumor penetrance due to their small size yet have an extended half-life due to HSA binding activity. ${ }^{134}$

\section{Novel delivery approaches}

As discussed previously, treatment penetrance into solid malignancies remains a particular challenge. Oncolytic viruses which deliver therapeutic transgenes can induce local expression of bispecific T-cell engagers and therefore stimulate tumor-resident $\mathrm{T}$ cells. ${ }^{135}{ }^{136}$ Scott et al developed both a bispecific and trispecific T-cell engager expressing adenovirus and demonstrated they could also be used to deplete immunosuppressive TAMs in vitro. ${ }^{137}$ This was further developed resulting in an oncolytic virus format which simultaneously produced IL-12, an antiPD-L1 antibody and a bispecific T-cell engager. In combination with CAR T-cell therapy, this format was able to kill multiple cancer cell lines expressing target antigen while inducing more durable responses against orthotopically implanted tumors. ${ }^{138}$ Oncolytic viruses such as adenovirus can also kill directly by oncolysis, which may further result in neoantigen release from within lysed cells. Their subsequent presentation by antigen-presenting cells could act as an in situ vaccine, enhancing the specific immune response further. ${ }^{139}$

Examples of combination therapies of CAR $\mathrm{T}$ cell and bispecific T-cell engagers are currently under preclinical evaluation in EGFRvIII expressing glioblastoma. Choi et al developed a bicistronic gene construct that enables coexpression of an EGFRvIII-directed CAR, which also secreted a bispecific T-cell engager targeting wild-type EGFR. These CAR $\mathrm{T}$ cells secreted bispecific T-cell engagers which successfully generated T-cell responses against EGFR wild type within the local tumor environment only in addition to EGFRvIII targeted tumor lysis by CARs. ${ }^{49}$ This resulted in successful clearance of heterogeneous glioblastoma in vivo, and the EGFR-targeting bispecific T-cell engager was only expressed in the local tumor environment, with no systemic detection. ${ }^{60}$ 
Of note, this effect was only seen when CAR-T therapy was delivered either intracerebrally or intraventricularly but lost if peripherally given. Similar intracranial approaches are also described by Gardell et al, who directly delivered a retrovirally modified macrophage which could secrete a bispecific T-cell engager specific for EGFRvIII to murine models of glioma. These macrophages could persist in the solid tumor, secreting both the bispecific T-cell engager therapy and IL-12, enhancing the T-cell response. ${ }^{140}$ However, as stated previously, while these approaches using CED bypass the BBB, these generally require an invasive procedure and can be hampered by uneven drug distribution/coverage at the tumor site. ${ }^{1516}$

\section{Targeting other TCRs}

Other experimental approaches involve modifying the structure of bispecific T-cell engagers to target other receptors. $\gamma-\delta$ T-cell engagers have been demonstrated to bind to a homogenous effector T-cell population with low levels of immune checkpoint molecule expression. ${ }^{141}$ Several of these constructs targeting non-CD3 TCRs, in combination with immune checkpoint blockade, are under evaluation (tumorous PD-L1 (NCT03917381), FAP (EudraCT 2017-000292-83), 4-1BB, LAG-3 (NCT04140500), and TIM-3 (NCT03752177)). Another modified approach includes that of dual-affinity retargeting (DART) proteins. These consist of bispecific diabodies with two variable fragment chains assembled by means of disulfide bonding and non-covalent forces. This results in a construct which can provide dual antigenbinding sites but may offer greater stability and enhanced redirection of T-cell killing towards tumor cells. ${ }^{142}$ Indeed, enhanced cytotoxicity when compared with traditional bispecific T-cell engagers has been observed in preclinical models, and DARTs are capable of redirecting NK cells and $\mathrm{T}$ cells in preclinical models of both hematological malignancies (anti-CD16-CD32B DART or antiCD19-CD3 DART duvortuxizumab (MGD011) and solid tumors (glycoprotein A33-expressing gastrointestinal cancer cells (gpA33;MGD007)). ${ }^{142-145}$

In glioblastoma, alongside bispecific T-cell engagers, bifunctional antibodies targeting EGFR and TGF- $\beta$ are undergoing evaluation (BCA101). This seeks to abrogate the potential for TGF- $\beta$ to induce regulatory T cells in the context of EGFR-driven malignancies (including glioblastoma). BCA101 is currently under evaluation in a phase I trial in advanced solid tumors refractory to standard of care as either a monotherapy or in combination with pembrolizumab, an FDA-approved mAb targeting PD-1 (NCT04429542). ${ }^{146}$ CDX-527 is another bispecific antibody under investigation for safety, tolerability and activity in multiple solid tumors (NCT04440943). This approach seeks to block the binding of PD-L1 while also including an agonist anti-CD27 domain. CD27 is a member of the tumor necrosis factor receptor family, and its blockade can enhance the immune response while reducing the number of $\mathrm{T}_{\text {regs }}$ in the local TME. ${ }^{147} 148$ This synergistic effect results in increased $\mathrm{CD}^{+}$T-cell expansion and effector function. ${ }^{149} 150$ These novel approaches currently under evaluation in glioblastoma are shown in figure 3 .

\section{CONCLUSIONS}

T-cell engagers are a specific and potent antitumor therapy which can overcome the barriers faced by traditional immunotherapy constructs when accessing immune privileged compartments such as the brain. However, significant challenges remain, such as the outgrowth of antigen-negative cells and the profoundly immunosuppressive microenvironment which negates T-cell function. For bispecific T-cell engagers to succeed, combination approaches will be required, possibly with ICI or cytokines, which may reinvigorate the immune response. As development of these molecules continues, it may be possible to merge these constructs into a single agent, although this may also enlarge its size and hamper its ability to cross the BBB. Although the short half-life of bispecific T-cell engagers does not pose an insurmountable clinical challenge, the need for a continuous infusion system makes this a complex therapy to administer at present, and more invasive administration systems will always carry a higher risk of morbidity. Other approaches to extending the half-life of bispecific T-cell engagers such as the addition of large stabilizing proteins may also be of value, but their effect on BBB migration dynamics must be carefully considered. While there are potential mechanisms to enhance trafficking across the BBB, our understanding of the exact mechanism and the degree of carriage into the CNS is not yet fully understood. Work to identify novel MHC independent antigens which are more universally expressed or whether partial killing can drive epitope spreading may also offer a way to overcome tumorous heterogeneity. Combinatorial approaches that can penetrate tumors, negate exhaustion, and drive the presentation of neoantigens to local $\mathrm{T}$ cells are likely to have the best chance of inducing efficacious and durable antitumor responses. Combination immunotherapies, however, bring their own challenges in determining the degree of attribution of individual components to efficacy and the potential for additive or synergistic toxicities. As greater numbers of T-cell engaging therapies in varying formats enter clinical trials in glioblastoma, the precise strategy and utility of these promising therapies will become more apparent.

\section{IMPORTANCE OF THE REVIEW}

We summarize the development of bispecific Tcell engagers in glioblastoma, including preclinical and clinical development to date. We explore future designs for Tcell engagers that may help to improve their efficacy and address unique aspects of Tcell engagers, such as their short half-life. Research using similar approaches with bispecific or multispecific antibodies is also elucidated. The unique challenges faced when using immunotherapy within the brain are contextualized with how 

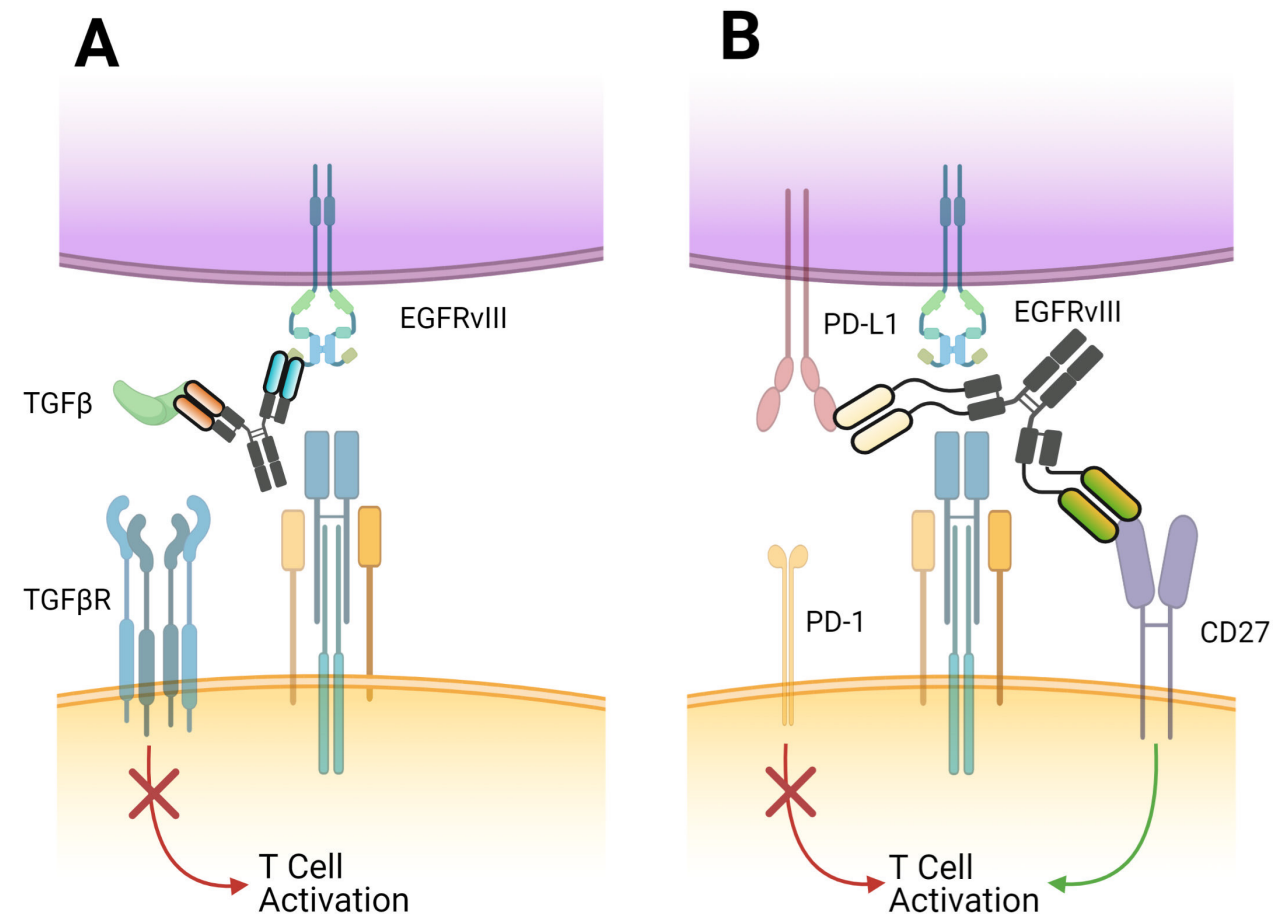

Figure 3 Novel bispecific approaches currently in phase I trials for glioblastoma. (A) EGFRxTGF- $\beta$ is a bifunctional antibody, which tethers to tumor cells via the EGFRvIll receptor but blocks the induction of regulatory T cells by binding of TGF- $\beta$, therefore preserving local effector T-cell function. This approach is currently being evaluated in phase I trials in multiple advanced solid tumors as either a monotherapy or combined with anti-PD1 agents (NCT04429542). (B) PD-L1xCD-27 is a bispecific antibody which blockades PD-L1 while also including an agonist anti-CD27 domain. Blockade of CD27 (a member of the Tumor Necrosis Factor family) can enhance the immune response while reducing the number of regulatory $T$ cells in the local tumor microenvironment. A phase I trial investigating this approach in multiple solid tumors including glioblastoma is currently under way (NCT04440943). PD-L1, programmed death ligand-1; TGF- $\beta$, transforming growth factor beta.

Tcell engagers may specifically address the hurdles facing development of effective immunotherapy in glioblastoma.

Twitter Aditya A Mohan @TheMohanAditya and Mustafa Khasraw @mkhasraw

Contributors MK, JHS, and KS conceived of and designed the work. KS performed the literature search and initially drafted and subsequently revised the manuscript. MK, JHS, KMH, JLR, and AAM developed the manuscript. KMH and AAM developed the figures, which were revised with input from KS and MK. All authors approved the documents for submission.

Funding The authors are supported by the following grants to Duke University: P50-CA190991 (SPORE) (JHS, MK), P01-CA225622 (JHS, MK), U01-NS090284 (JHS), R01-NS099463 (JHS), R01-CA175517 (JHS), and R01-CA235612 (JHS, MK).

Competing interests $\mathrm{KS}, \mathrm{KLH}$, JMR, and AAM declare no conflicts of interest. JHS has an equity interest in Annias Immunotherapeutics, which has licensed intellectual property from Duke related to the use of the pepCMV vaccine in the treatment of glioblastoma multiforme. JHS has an equity interest in Istari Oncology, which has licensed intellectual property from Duke related to the use of poliovirus and D2C7 in the treatment of glioblastoma. JHS is an inventor on patents related to PEP-CMV DC vaccine with tetanus, as well as poliovirus vaccine and D2C7 in the treatment of glioblastoma. MK reports personal fees from Jackson Laboratory for Genomic Medicine and research funding from AbbVie and Bristol-Myers Squibb were paid to his institution for glioblastoma research.

Patient consent for publication Not applicable.

Provenance and peer review Commissioned; externally peer reviewed.

Open access This is an open access article distributed in accordance with the Creative Commons Attribution Non Commercial (CC BY-NC 4.0) license, which permits others to distribute, remix, adapt, build upon this work non-commercially, and license their derivative works on different terms, provided the original work is properly cited, appropriate credit is given, any changes made indicated, and the use is non-commercial. See http://creativecommons.org/licenses/by-nc/4.0/.
ORCID iD

Mustafa Khasraw http://orcid.org/0000-0003-3249-9849

\section{REFERENCES}

1 Stupp R, Mason WP, van den Bent MJ, et al. Radiotherapy plus concomitant and adjuvant temozolomide for glioblastoma. $N$ Engl $J$ Med 2005;352:987-96.

2 Tan AC, Ashley DM, López GY, et al. Management of glioblastoma: state of the art and future directions. CA Cancer J Clin 2020:70:299-312

3 Bagley SJ, Kothari S, Rahman R, et al. Glioblastoma clinical trials: current landscape and opportunities for improvement. Clin Cancer Res 2021.

4 Gong J, Chehrazi-Raffle A, Reddi S, et al. Development of PD-1 and PD-L1 inhibitors as a form of cancer immunotherapy: a comprehensive review of registration trials and future considerations. J Immunother Cancer 2018;6:8.

5 Chuntova P, Chow F, Watchmaker P. Unique challenges for glioblastoma immunotherapy - Discussions across neuro-oncology and non-neuro-oncology experts in cancer immunology. Neuro Oncol 2020.

6 Khasraw M, Reardon DA, Weller M, et al. PD-1 inhibitors: do they have a future in the treatment of glioblastoma? Clin Cancer Res 2020;26:5287-96.

7 Labrijn AF, Janmaat ML, Reichert JM, et al. Bispecific antibodies: a mechanistic review of the pipeline. Nat Rev Drug Discov 2019;18:585-608.

8 Pardoll DM. The blockade of immune checkpoints in cancer immunotherapy. Nat Rev Cancer 2012;12:252-64.

9 Portnow J, Wang D, Blanchard MS, et al. Systemic anti-PD-1 immunotherapy results in PD-1 blockade on T cells in the cerebrospinal fluid. JAMA Oncol 2020;6:1947-51.

10 Weber FW, Floeth F, Asher A, et al. Local convection enhanced delivery of IL4-pseudomonas exotoxin (NBI-3001) for treatment 
of patients with recurrent malignant glioma. Acta Neurochir Supp/ 2003;88:93-103.

11 Kunwar S, Chang SM, Prados MD, et al. Safety of intraparenchymal convection-enhanced delivery of cintredekin besudotox in earlyphase studies. Neurosurg Focus 2006;20:E15.

12 Kunwar S, Prados MD, Chang SM, et al. Direct intracerebral delivery of cintredekin besudotox (IL13-PE38QQR) in recurrent malignant glioma: a report by the Cintredekin Besudotox intraparenchymal Study Group. J Clin Oncol 2007;25:837-44.

13 Mazor R, Onda M, Pastan I. Immunogenicity of therapeutic recombinant immunotoxins. Immunol Rev 2016;270:152-64.

14 Mazor R, Pastan I. Immunogenicity of immunotoxins containing Pseudomonas exotoxin A: causes, consequences, and mitigation. Front Immunol 2020;11:1261.

15 Sampson JH, Archer G, Pedain C, et al. Poor drug distribution as a possible explanation for the results of the precise trial. J Neurosurg 2010;113:301-9.

16 Brady M, Raghavan R, Sampson J. Determinants of intraparenchymal infusion distributions: modeling and analyses of human glioblastoma trials. Pharmaceutics 2020;12 doi:10.3390/ pharmaceutics12090895

17 Brinkmann U, Kontermann RE. The making of bispecific antibodies. MAbs 2017:9:182-212.

18 Spiess C, Zhai Q, Carter PJ. Alternative molecular formats and therapeutic applications for bispecific antibodies. Mol Immunol 2015;67:95-106

19 Dreier T, Lorenczewski G, Brandl C, et al. Extremely potent, rapid and costimulation-independent cytotoxic T-cell response against lymphoma cells catalyzed by a single-chain bispecific antibody. Int J Cancer 2002;100:690-7.

20 Offner S, Hofmeister R, Romaniuk A, et al. Induction of regular cytolytic $T$ cell synapses by bispecific single-chain antibody constructs on MHC class I-negative tumor cells. Mol Immunol 2006;43:763-71.

21 Yeung JT, Hamilton RL, Ohnishi K, et al. LOH in the HLA class I region at 6 p21 is associated with shorter survival in newly diagnosed adult glioblastoma. Clin Cancer Res 2013;19:1816-26.

22 Johanns TM, Bowman-Kirigin JA, Liu C, et al. Targeting neoantigens in glioblastoma: an overview of cancer Immunogenomics and translational implications. Neurosurgery 2017;64:165-76.

23 Learn CA, Fecci PE, Schmittling RJ, et al. Profiling of CD4+, $\mathrm{CD} 8+$, and $\mathrm{CD} 4+\mathrm{CD} 25+\mathrm{CD} 45 \mathrm{RO}+\mathrm{FoxP} 3+\mathrm{T}$ cells in patients with malignant glioma reveals differential expression of the immunologic transcriptome compared with T cells from healthy volunteers. Clin Cancer Res 2006;12:7306-15.

24 O'Rourke DM, Nasrallah MP, Desai A, et al. A single dose of peripherally infused EGFRvIll-directed CAR T cells mediates antigen loss and induces adaptive resistance in patients with recurrent glioblastoma. Sci Trans/ Med 2017:9 doi:10.1126/scitranslmed. aaa0984

25 Sampson JH, Heimberger AB, Archer GE, et al. Immunologic escape after prolonged progression-free survival with epidermal growth factor receptor variant III peptide vaccination in patients with newly diagnosed glioblastoma. J Clin Oncol 2010;28:4722-9.

26 Brown CE, Alizadeh D, Starr R, et al. Regression of glioblastoma after chimeric antigen receptor T-cell therapy. $N$ Engl J Med 2016;375:2561-9.

27 FDA grants regular approval to blinatumomab and expands indication to include Philadelphia chromosome-positive B cell ] FDA. Available: https://www.fda.gov/drugs/resources-informationapproved-drugs/fda-grants-regular-approval-blinatumomab-andexpands-indication-include-philadelphia-chromosome

28 Einsele H, Rasche L, Topp MS, et al. The use of bispecific antibodies to optimize the outcome of patients with acute leukemia, lymphoma and multiple myeloma after SCT. Bone Marrow Transplant 2019;54:721-6.

29 Wang Q, Chen Y, Park J, et al. Design and production of bispecific antibodies. Antibodies 2019;8:43.

30 Nagorsen D, Kufer P, Baeuerle PA, et al. Blinatumomab: a historical perspective. Pharmacol Ther 2012;136:334-42.

31 Aldoss I, Bargou RC, Nagorsen D, et al. Redirecting T cells to eradicate B-cell acute lymphoblastic leukemia: bispecific T-cell engagers and chimeric antigen receptors. Leukemia 2017;31:777-87.

32 Topp MS, Kufer P, Gökbuget N, et al. Targeted therapy with the T-cell-engaging antibody blinatumomab of chemotherapy-refractory minimal residual disease in B-lineage acute lymphoblastic leukemia patients results in high response rate and prolonged leukemia-free survival. J Clin Oncol 2011;29:2493-8.

33 Choi BD, Gedeon PC, Herndon JE, et al. Human regulatory T cells kill tumor cells through granzyme-dependent cytotoxicity upon retargeting with a bispecific antibody. Cancer Immunol Res 2013:1:163-7.

34 Choi BD, Gedeon PC, Sanchez-Perez L, et al. Regulatory T cells are redirected to kill glioblastoma by an EGFRvIll-targeted bispecific antibody. Oncoimmunology 2013;2:e26757.

35 Hoffmann P, Hofmeister R, Brischwein K, et al. Serial killing of tumor cells by cytotoxic T cells redirected with a CD19-/CD3-bispecific single-chain antibody construct. Int $J$ Cancer 2005;115:98-104.

36 Shah NN, Fry TJ. Mechanisms of resistance to CAR T cell therapy. Nat Rev Clin Oncol 2019;16:372-85.

37 Mack M, Riethmüller G, Kufer P. A small bispecific antibody construct expressed as a functional single-chain molecule with high tumor cell cytotoxicity. Proc Natl Acad Sci U S A 1995:92:7021-5.

38 Löffler $A$, Kufer $P$, Lutterbüse $R$, et al. A recombinant bispecific single-chain antibody, CD19 $\times$ CD3, induces rapid and high lymphoma-directed cytotoxicity by unstimulated T lymphocytes. Blood 2000;95:2098-103.

39 Dreier T, Baeuerle PA, Fichtner I, et al. T cell costimulusindependent and very efficacious inhibition of tumor growth in mice bearing subcutaneous or leukemic human B cell lymphoma xenografts by a CD19-/CD3- bispecific single-chain antibody construct. J Immunol 2003;170:4397-402.

40 Löffler A, Gruen M, Wuchter C, et al. Efficient elimination of chronic lymphocytic leukaemia B cells by autologous $T$ cells with a bispecific anti-CD19/anti-CD3 single-chain antibody construct. Leukemia 2003;17:900-9.

41 Löffler A, Kufer P, Lutterbüse R, et al. A recombinant bispecific single-chain antibody, CD19 X CD3, induces rapid and high lymphoma-directed cytotoxicity by unstimulated T lymphocytes. Blood 2000;95:2098-103.

42 Gabrielsson J, Peletier LA, Hjorth S. In vivo potency revisited - Keep the target in sight. Pharmacol Ther 2018;184:177-88.

43 Jansson-Löfmark R, Hjorth S, Gabrielsson J. Does in vitro potency predict clinically efficacious concentrations? Clin Pharmacol Ther 2020;108:298-305.

44 Platten $\mathrm{M}$, Bunse $\mathrm{L}$, Wick $\mathrm{A}$, et al. A vaccine targeting mutant IDH1 in newly diagnosed glioma. Nature 2021;592:463-8.

45 Sigismund S, Avanzato D, Lanzetti L. Emerging functions of the EGFR in cancer. Mol Oncol 2018;12:3-20.

46 Gan HK, Kaye AH, Luwor RB. The EGFRvIll variant in glioblastoma multiforme. J Clin Neurosci 2009;16:748-54.

47 Scott AM, Lee F-T, Tebbutt N, et al. A phase I clinical trial with monoclonal antibody ch806 targeting transitional state and mutant epidermal growth factor receptors. Proc Natl Acad Sci U S A 2007;104:4071-6.

48 Sarkaria JN, Hu LS, Parney IF, et al. Is the blood-brain barrier really disrupted in all glioblastomas? A critical assessment of existing clinical data. Neuro Oncol 2018;20:184-91.

49 Choi BD, O'Rourke DM, Maus MV. Engineering chimeric antigen receptor T cells to treat glioblastoma. J Target Ther Cancer 2017;6:22-5.

50 Brown CE, Badie B, Barish ME, et al. Bioactivity and safety of IL13R $\alpha 2$-redirected chimeric antigen receptor CD8+ T cells in patients with recurrent glioblastoma. Clin Cancer Res 2015;21:4062-72.

51 Braig F, Brandt A, Goebeler M, et al. Resistance to anti-CD19/ CD3 BiTE in acute lymphoblastic leukemia may be mediated by disrupted CD19 membrane trafficking. Blood 2017;129:100-4.

52 Brudno JN, Kochenderfer JN. Recent advances in CAR T-cell toxicity: mechanisms, manifestations and management. Blood Rev 2019;34:45-55.

53 Jabbour E, Düll J, Yilmaz M, et al. Outcome of patients with relapsed/refractory acute lymphoblastic leukemia after blinatumomab failure: no change in the level of CD19 expression. Am J Hematol 2018;93:371-4.

54 Hegde M, Mukherjee M, Grada Z, et al. Tandem CAR T cells targeting HER2 and IL13R $\alpha 2$ mitigate tumor antigen escape. J Clin Invest 2016;126:3036-52.

55 Majzner RG, Mackall CL. Tumor antigen escape from CAR T-cell therapy. Cancer Discov 2018;8:1219-26.

56 Guedan S, Ruella M, June $\mathrm{CH}$. Emerging cellular therapies for cancer. Annu Rev Immunol 2019;37:145-71.

57 Ross SL, Sherman M, McElroy PL, et al. Bispecific T cell engager (BiTE $®)$ antibody constructs can mediate bystander tumor cell killing. PLoS One 2017;12:e0183390.

58 Lanitis E, Poussin M, Hagemann IS, et al. Redirected antitumor activity of primary human lymphocytes transduced with a fully human anti-mesothelin chimeric receptor. Mol Ther 2012;20:633-43. 
59 Krenciute G, Prinzing BL, Yi Z, et al. Transgenic expression of IL15 improves antiglioma activity of IL13R $\alpha 2-C A R T$ cells but results in antigen loss variants. Cancer Immunol Res 2017;5:571-81.

60 Choi BD, Yu X, Castano AP, et al. CAR-T cells secreting BiTEs circumvent antigen escape without detectable toxicity. Nat Biotechnol 2019;37:1049-58.

61 Fan D, Li W, Yang Y, et al. Redirection of CD4+ and CD8+ T lymphocytes via an anti-CD3 $\times$ anti-CD19 bi-specific antibody combined with cytosine arabinoside and the efficient lysis of patient-derived B-ALL cells. J Hematol Oncol 2015;8:1-12.

62 Li J, Stagg NJ, Johnston J, et al. Membrane-proximal epitope facilitates efficient $\mathrm{T}$ cell synapse formation by Anti-FcRH5/ CD3 and is a requirement for myeloma cell killing. Cancer Cell 2017;31:383-95.

63 Schaller TH, Foster MW, Thompson JW, et al. Pharmacokinetic Analysis of a Novel Human EGFRvIll:CD3 Bispecific Antibody in Plasma and Whole Blood Using a High-Resolution Targeted Mass Spectrometry Approach. J Proteome Res 2019;18:3032-41.

64 Topp MS, Gökbuget N, Zugmaier G, et al. Phase II trial of the anti-CD19 bispecific T cell-engager blinatumomab shows hematologic and molecular remissions in patients with relapsed or refractory B-precursor acute lymphoblastic leukemia. J Clin Oncol 2014:32:4134-40.

65 Bates A, Power CA. David vs. Goliath: the structure, function, and clinical prospects of antibody fragments. Antibodies 2019;8:1:28. doi:10.3390/antib8020028

66 Kontermann RE. Half-life extended biotherapeutics. Expert Opin Biol Ther 2016;16:903-15. doi:10.1517/14712598.2016.1165661

67 Faber MS, Lee S-H, Kim YK. Abstract 1860: bispecific claudin-6 $X$ CD3 antibodies in a $2+1$ format demonstrate selectivity and activity on human ovarian cancer cells. Cancer Res 2021;81:1860

68 Nisthal A, Lee S-H, Kim YK. Abstract 2286: XmAb30819, an XmAb2+1 ENPP3 x CD3 bispecific antibody for RCC, demonstrates safety and efficacy in in vivo preclinical studies. Cancer Res 2020;80:2286.

69 Nisthal A, Dragovich M, Pong EW. Abstract 5663: Affinity tuned XmAb2+1 PSMA x CD3 bispecific antibodies demonstrate selective activity in prostate cancer models. Cancer Res 2020;80:5663.

70 Deegen P, Thomas O, Nolan-Stevaux O, et al. The PSMA-targeting half-life extended BiTE therapy AMG 160 has potent antitumor activity in preclinical models of metastatic castration-resistant prostate cancer. Clin Cancer Res 2021;27:2928-37.

71 Popplewell L, Verhoef G, Kuruvilla J, et al. A first-in-human study of a half-life extended CD19-TARGETING bite in relapsed/refractory diffuse large B cell lymphoma, mantle cell lymphoma or follicular lymphoma. Hematol Oncol 2019;37:566-7.

72 Davé E, Adams R, Zaccheo O, et al. Fab-dsFv: a bispecific antibody format with extended serum half-life through albumin binding. MAbs 2016;8:1319-35.

73 Gregory JV, Kadiyala P, Doherty R, et al. Systemic brain tumor delivery of synthetic protein nanoparticles for glioblastoma therapy. Nat Commun 2020;11:5687.

74 Tomaszewski W, Sanchez-Perez L, Gajewski TF. Brain tumor microenvironment and host state: implications for immunotherapy, 2019.

75 Wiendl $\mathrm{H}$, Mitsdoerffer M, Hofmeister V, et al. A functional role of HLA-G expression in human gliomas: an alternative strategy of immune escape. J Immunol 2002;168:4772-80.

76 Zhang X, Rao A, Sette P, et al. IDH mutant gliomas escape natural killer cell immune surveillance by downregulation of NKG2D ligand expression. Neuro Oncol 2016:18:1402-12.

77 Law TM, Motzer RJ, Mazumdar M, et al. Phase III randomized trial of interleukin-2 with or without lymphokine-activated killer cells in the treatment of patients with advanced renal cell carcinoma. Cancer 1995;76:824-32

78 Castriconi R, Daga A, Dondero A, et al. NK cells recognize and kill human glioblastoma cells with stem cell-like properties. J Immunol 2009;182:3530-9.

79 Kmiecik J, Poli A, Brons NHC, et al. Elevated CD3+ and CD8+ tumor-infiltrating immune cells correlate with prolonged survival in glioblastoma patients despite integrated immunosuppressive mechanisms in the tumor microenvironment and at the systemic level. J Neuroimmunol 2013;264:71-83.

80 El Andaloussi A, Lesniak MS. An increase in CD4+CD25+FOXP3+ regulatory $T$ cells in tumor-infiltrating lymphocytes of human glioblastoma multiforme. Neuro Oncol 2006;8:234-43.

81 Reardon DA, Brandes AA, Omuro A, et al. Effect of nivolumab vs bevacizumab in patients with recurrent glioblastoma: the CheckMate 143 phase 3 randomized clinical trial. JAMA Oncol 2020;6:1003-10.
82 Thornton AM, Shevach EM. CD4+CD25+ immunoregulatory T cells suppress polyclonal $\mathrm{T}$ cell activation in vitro by inhibiting interleukin 2 production. J Exp Med 1998;188:287-96.

83 Uyttenhove C, Pilotte L, Théate I, et al. Evidence for a tumoral immune resistance mechanism based on tryptophan degradation by indoleamine 2,3-dioxygenase. Nat Med 2003;9:1269-74.

84 Long GV, Dummer R, Hamid O, et al. Epacadostat plus pembrolizumab versus placebo plus pembrolizumab in patients with unresectable or metastatic melanoma (ECHO-301/KEYNOTE-252): a phase 3, randomised, double-blind study. Lancet Oncol 2019;20:1083-97.

85 Opitz CA, Litzenburger UM, Sahm F, et al. An endogenous tumourpromoting ligand of the human aryl hydrocarbon receptor. Nature 2011;478:197-203.

86 Sadik A, Somarribas Patterson LF, Öztürk S, et al. IL4I1 is a metabolic immune checkpoint that activates the AhR and promotes tumor progression. Cell 2020;182:1252-70.

87 Vitkovic L, Maeda S, Sternberg E. Anti-inflammatory cytokines: expression and action in the brain. Neuroimmunomodulation 2001:9:295-312.

88 Gong D, Shi W, Yi S-ju, et al. TGF $\beta$ signaling plays a critical role in promoting alternative macrophage activation. BMC Immunol 2012;13:31.

89 Haas R, Smith J, Rocher-Ros V, et al. Lactate regulates metabolic and pro-inflammatory circuits in control of T cell migration and effector functions. PLoS Biol 2015;13:e1002202.

90 Lim AR, Rathmell WK, Rathmell JC. The tumor microenvironment as a metabolic barrier to effector $T$ cells and immunotherapy. eLife 2020;9.

91 Palazon A, Tyrakis PA, Macias D, et al. An HIF-1alpha/VEGF-A axis in cytotoxic T cells regulates tumor progression. Cancer Cell 2017;32:e665:669-83.

92 Palazon A, Tyrakis PA, Macias D, et al. An HIF-1 $\alpha /$ VEGF-A axis in cytotoxic T cells regulates tumor progression. Cancer Cell 2017;32:669-83.

93 Lanitis E, Dangaj D, Irving M, et al. Mechanisms regulating T-cell infiltration and activity in solid tumors. Ann Oncol 2017;28:xii18-32.

94 Mardiana S, Solomon BJ, Darcy PK, et al. Supercharging adoptive T cell therapy to overcome solid tumor-induced immunosuppression. Sci Transl Med 2019;11 doi:10.1126/scitransImed.aaw2293

95 Liu X, Ranganathan R, Jiang S, et al. A chimeric switch-receptor targeting PD1 augments the efficacy of second-generation CAR T cells in advanced solid tumors. Cancer Res 2016;76:1578-90.

96 Slaney CY, Wang P, Darcy PK, et al. CARs versus BiTEs: a comparison between T Cell-Redirection strategies for cancer treatment. Cancer Discov 2018;8:924-34.

97 Hurton LV, Singh H, Najjar AM, et al. Tethered IL-15 augments antitumor activity and promotes a stem-cell memory subset in tumor-specific T cells. Proc Natl Acad Sci U S A 2016;113:E7788-97.

98 Avanzi MP, Yeku O, Li X, et al. Engineered tumor-targeted T cells mediate enhanced anti-tumor efficacy both directly and through activation of the endogenous immune system. Cell Rep 2018:23:2130-41.

99 Frewert S, Stockhammer F, Warschewske G, et al. Intratumoral infusion of interleukin-1beta and interferon-gamma induces tumor invasion with macrophages and lymphocytes in a rat glioma model. Neurosci Lett 2004;364:145-8.

100 Caruana I, Savoldo B, Hoyos V, et al. Heparanase promotes tumor infiltration and antitumor activity of CAR-redirected T lymphocytes. Nat Med 2015;21:524-9.

101 Wang L-CS, Lo A, Scholler J, et al. Targeting fibroblast activation protein in tumor stroma with chimeric antigen receptor T cells can inhibit tumor growth and augment host immunity without severe toxicity. Cancer Immunol Res 2014;2:154-66.

102 Choi BD, Kuan C-T, Cai M, et al. Systemic administration of a bispecific antibody targeting EGFRvIll successfully treats intracerebral glioma. Proc Natl Acad Sci U S A 2013;110:270-5.

103 Weigelin B, den Boer AT, Wagena E, et al. Cytotoxic T cells are able to efficiently eliminate cancer cells by additive cytotoxicity. Nat Commun 2021;12:5217.

104 Thomas DA, Du C, Xu M, et al. DFF45/ICAD can be directly processed by granzyme $B$ during the induction of apoptosis. Immunity 2000;12:621-32.

105 Gedeon PC, Schaller TH, Chitneni SK, et al. A rationally designed fully human EGFRvIll:CD3-targeted bispecific antibody redirects human $T$ cells to treat patient-derived intracerebral malignant glioma. Clin Cancer Res 2018;24:3611-31.

106 Gaston RS, Deierhoi MH, Patterson T, et al. OKT3 first-dose reaction: association with $\mathrm{T}$ cell subsets and cytokine release. Kidney Int 1991;39:141-8. 
107 Reynolds JC, Del Vecchio S, Sakahara H, et al. Anti-murine antibody response to mouse monoclonal antibodies: clinical findings and implications. Int J Rad Appl Instrum B 1989;16:121-5.

108 Kuus-Reichel K, Grauer LS, Karavodin LM, et al. Will immunogenicity limit the use, efficacy, and future development of therapeutic monoclonal antibodies? Clin Diagn Lab Immunol 1994:1:365-72.

109 Mascelli MA, Zhou H, Sweet R, et al. Molecular, biologic, and pharmacokinetic properties of monoclonal antibodies: impact of these parameters on early clinical development. J Clin Pharmacol 2007;47:553-65.

110 Schaller TH, Snyder DJ, Spasojevic I, et al. First in human dose calculation of a single-chain bispecific antibody targeting glioma using the MABEL approach. J Immunother Cancer 2020;8:e000213.

111 Amann M, D'Argouges S, Lorenczewski G, et al. Antitumor activity of an EpCAM/CD3-bispecific BiTE antibody during long-term treatment of mice in the absence of T-cell anergy and sustained cytokine release. J Immunother 2009;32:452-64.

112 Dreier T, Baeuerle PA, Fichtner I, et al. T cell costimulusindependent and very efficacious inhibition of tumor growth in mice bearing subcutaneous or leukemic human B cell lymphoma xenografts by a CD19-/CD3- bispecific single-chain antibody construct. J Immunol 2003;170:4397-402.

113 Amann M, Friedrich M, Lutterbuese P, et al. Therapeutic window of an EpCAM/CD3-specific BiTE antibody in mice is determined by a subpopulation of EpCAM-expressing lymphocytes that is absent in humans. Cancer Immunol Immunother 2009;58:95-109.

114 Gedeon PC, Streicker MA, Schaller TH, et al. GLP toxicology study of a fully-human T cell redirecting CD3:EGFRvIll binding immunotherapeutic bispecific antibody. PLoS One 2020;15:e0236374

115 Rosenthal M, Balana C, Van Linde ME, et al. Novel anti-EGFRvIll bispecific T cell engager (BiTE) antibody construct in glioblastoma (GBM): trial in progress of AMG 596 in patients with recurrent or newly diagnosed disease. Journal of Clinical Oncology 2019;37:TPS2071.

116 Syn NL, Teng MWL, Mok TSK, et al. De-novo and acquired resistance to immune checkpoint targeting. Lancet Oncol 2017;18:e731-41

117 Amgen reports fourth quarter and full year 2020 financial results. Available: https://www.prnewswire.com/news-releases/amgenreports-fourth-quarter-and-full-year-2020-financial-results301220622.html

118 van der Woude CJ, Stokkers P, van Bodegraven AA, et al. Phase I, double-blind, randomized, placebo-controlled, dose-escalation study of NI-0401 (a fully human anti-CD3 monoclonal antibody) in patients with moderate to severe active Crohn's disease. Inflamm Bowel Dis 2010;16:1708-16.

119 Dean Y, Dépis F, Kosco-Vilbois M. Combination therapies in the context of anti-CD3 antibodies for the treatment of autoimmune diseases. Swiss Med Wkly 2012;142:w13711.

120 Weber R, Feng X, Foord O. Antibodies directed to the deletion mutants of epidermal growth factor receptor and uses thereof. Google Patents, 2009.

121 Gabrilovich D, Pisarev V. Tumor escape from immune response: mechanisms and targets of activity. Curr Drug Targets 2003;4:525-36.

122 Yang I, Tihan T, Han SJ, et al. CD8+ T-cell infiltrate in newly diagnosed glioblastoma is associated with long-term survival. $J$ Clin Neurosci 2010;17:1381-5.

123 Lohr J, Ratliff T, Huppertz A, et al. Effector T-cell infiltration positively impacts survival of glioblastoma patients and is impaired by tumor-derived TGF- $\beta$. Clin Cancer Res 2011;17:4296-308.

124 Dudley ME, Rosenberg SA. Adoptive-cell-transfer therapy for the treatment of patients with cancer. Nat Rev Cancer 2003;3:666-75.

125 Klinger M, Zugmaier G, Nägele V, et al. Adhesion of T cells to endothelial cells facilitates Blinatumomab-Associated neurologic adverse events. Cancer Res 2020;80:91-101.

126 Gust J, Hay KA, Hanafi L-A, et al. Endothelial activation and blood-brain barrier disruption in neurotoxicity after adoptive immunotherapy with CD19 CAR-T cells. Cancer Discov 2017:7:1404-19.

127 Lum LG, Thakur A, Choi M, et al. Clinical and immune responses to anti-CD3 $X$ anti-EGFR bispecific antibody armed activated T cells (EGFR bats) in pancreatic cancer patients. Oncoimmunology 2020;9:1773201.
128 Phase I EGFR BATs in newly diagnosed glioblastoma. Available: https://clinicaltrials.gov/ct2/show/NCT03344250

129 Herrmann M, Krupka C, Deiser K, et al. Bifunctional PD- $1 \times \alpha C D 3$ $\times \alpha C D 33$ fusion protein reverses adaptive immune escape in acute myeloid leukemia. Blood 2018;132:2484-94.

130 Correnti CE, Laszlo GS, de van der Schueren WJ, et al. Simultaneous multiple interaction T-cell engaging (SMITE) bispecific antibodies overcome bispecific T-cell engager (BiTE) resistance via CD28 co-stimulation. Leukemia 2018;32:1239-43.

131 Esensten JH, Helou YA, Chopra G, et al. Bluestone costimulation: from mechanism to therapy. Immunity 2016;44:973-88.

132 Wu L, Seung E, Xu L, et al. Trispecific antibodies enhance the therapeutic efficacy of tumor-directed T cells through $\mathrm{T}$ cell receptor co-stimulation. Nat Cancer 2020;1:86-98.

133 Do P, Perdue LA, Chyong A. Promoting anti-tumor immunity via bispecific T cell engaging cytokine (biteokine) therapy. J Immunol 2020;204:169.122.

134 Austin RJ, Lemon BD, Aaron WH, et al. TriTACs, a novel class of Tcell-engaging protein constructs designed for the treatment of solid tumors. Mol Cancer Ther 2021;20:109-20.

135 Scott EM, Duffy MR, Freedman JD. Solid tumor immunotherapy with T cell Engager-Armed oncolytic viruses. Macromol Biosci 2018;18 doi:10.1002/mabi.201700187

136 Fajardo CA, Guedan S, Rojas LA, et al. Oncolytic adenoviral delivery of an EGFR-Targeting T-cell Engager improves antitumor efficacy. Cancer Res 2017:77:2052-63.

137 Scott EM, Jacobus EJ, Lyons B, et al. Bi- and tri-valent T cell engagers deplete tumour-associated macrophages in cancer patient samples. J Immunother Cancer 2019;7:320.

138 Porter CE, Rosewell Shaw A, Jung Y, et al. Oncolytic adenovirus armed with bite, cytokine, and checkpoint inhibitor enables CAR $\mathrm{T}$ cells to control the growth of heterogeneous tumors. Mol Ther 2020;28:1251-62.

139 Speck T, Heidbuechel JPW, Veinalde R, et al. Targeted BiTE expression by an oncolytic vector augments therapeutic efficacy against solid tumors. Clin Cancer Res 2018:24:2128-37.

140 Gardell JL, Matsumoto LR, Chinn H, et al. Human macrophages engineered to secrete a bispecific $\mathrm{T}$ cell engager support antigendependent T cell responses to glioblastoma. J Immunother Cancer 2020;8:e001202.

141 Ellerman D. Bispecific T-cell engagers: towards understanding variables influencing the in vitro potency and tumor selectivity and their modulation to enhance their efficacy and safety. Methods 2019;154:102-17.

142 Johnson S, Burke S, Huang L, et al. Effector cell recruitment with novel Fv-based dual-affinity re-targeting protein leads to potent tumor cytolysis and in vivo B-cell depletion. $J$ Mol Biol 2010;399:436-49.

143 Moore PA, Shah K, Yang Y, et al. Development of MGD007, a gpA33 X CD3-Bispecific DART protein for T-cell immunotherapy of metastatic colorectal cancer. Mol Cancer Ther 2018;17:1761-72.

144 Moore PA, Zhang W, Rainey GJ, et al. Application of dual affinity retargeting molecules to achieve optimal redirected T-cell killing of B-cell lymphoma. Blood 2011;117:4542-51.

145 Liu L, Lam C-YK, Long V, et al. MGD011, a CD19 X CD3 dualaffinity retargeting bi-specific molecule incorporating extended circulating half-life for the treatment of B-cell malignancies. Clin Cancer Res 2017;23:1506-18.

146 Study of safety and tolerability of BCA101 alone and in combination with pembrolizumab in patients with EGFR-driven advanced solid tumors. Available: https://clinicaltrials.gov/ct2/ show/NCT04429542

147 Tesselaar K, Gravestein LA, van Schijndel GM, et al. Characterization of murine $\mathrm{CD} 70$, the ligand of the TNF receptor family member CD27. J Immunol 1997;159:4959-65.

148 Hintzen RQ, Lens SM, Lammers K, et al. Engagement of CD27 with its ligand CD70 provides a second signal for T cell activation. $J$ Immunol 1995;154:2612-23.

149 Buchan SL, Fallatah M, Thirdborough SM, et al. PD-1 blockade and CD27 stimulation activate distinct transcriptional programs that synergize for $\mathrm{CD}^{+} \mathrm{T}$-cell-driven antitumor immunity. Clin Cancer Res 2018;24:2383-94.

150 A study of the PD-L1XCD27 bispecific antibody CDX-527 in patients with advanced malignancies. Available: https://clinicaltrials.gov/ct2/ show/NCT04440943 